\title{
Epidermal inclusion cyst of the penis after urethroplasty causing an urethro-cutaneous fistula: a first case report
}

\author{
Cisti epidermoide del pene causa di fistola uretro-cutanea dopo uretroplastica: primo case report.
}

A. Giambanco, ${ }^{1}$ M. Pensabene, ${ }^{1}$ M. Giuffrè, ${ }^{1}$ M. Cimador ${ }^{1}$

Key words: epidermal cyst; hypospadias; urethra-cutaneous fistula; pediatric

\begin{abstract}
Penile epidermal cysts are uncommon. We report a pediatric case of epidermal inclusion cyst of the penis after urethroplasty, responsible of the appearance of an urethro-cutaneous fistula. In our opinion, surgical excision of epidermal inclusion cyst after urethroplasty must be performed as quickly as possible to avoid occurrence of postoperative complications.

Le cisti epidermoidi del pene sono rare. Si riporta il primo caso in età pediatrica di una cisti da inclusione epiteliale del pene secondaria a chirurgia dell'ipospadia, responsabile della formazione di una fistola uretro-cutanea. Noi riteniamo che la exeresi chirurgica di queste cisti dovrebbe essere eseguita precocemente al fine di evitare l'insorgenza di complicanze postoperatorie nella chirurgia dell'ipospadia.
\end{abstract}

\section{Introduction}

Penile epidermal cysts are uncommon. They can be congenital or acquired. Congenital forms may represent the result of abnormal embryologic closure of the median raphe. Acquired forms result from the inclusion of epidermal cells within a circumscribed space of the dermis, usually after penile surgery or trauma. (1) We report the first pediatric case of epidermal inclusion cyst of the penis after urethroplasty, in our opinion responsible of the apparence of an urethro-cutaneous fistula Pediatric Urology, Dept. Of Science for Health Promotion and Mother \& Child Care,
Università di Palermo, Palermo, Italy

Indirizzo per la corrispondenza (Corresponding author):

Marcello Cimador, MD

Università di Palermo - Dipartimento Materno-Infantile

Via A.Giordano, 3 - 90127 Palermo - Italy

Tel. 0039-0916555466 - Fax. 0039-0916555419

marcello.cimador@unipa.it

\section{Case report}

We report a case of 2-year old boy with an anterior hypospadias underwent urethroplasty with Snodgrass procedure. The urethroplasty was covered with dorsal subcutaneous flaps (2) from prepuce according to Retik. Circumcision was performed. The post-operative follow-up was uneventful until 1 year after the surgical procedure, when the boy came back to our attention because of the appearance of an urethro-cutaneous fistula (Fig.1-2). The penile examination revealed the presence of an asymptomatic soft mass in the ventral aspect of the shaft, just below the balanic groove. Initially it was quite small, but it started to grow rapidly up to $1.5 \mathrm{~cm}$. The flesh-colored elastic mass with a smooth surface and restricted mobility was painless. After a careful evaluation we detected a pinpoint urethro-cutaneous fistula at the top of the cystic lesion. So we have decided to threat the urethro-cutaneous fistula and to remove the cystic mass. Macroscopically the cut surface was characterized by the presence of a cheesy material. Histopathological examination revealed an epidermal inclusion cyst. There is no recurrence at 6months follow-up.

\section{Discussion}

Epidermal cysts may arise from all part of the body, but penile localization is rare. They can be congenital or acquired. Congenital forms may represent the result of abnormal embryologic closure of the median raphe. (3) Than they can occur anywhere along the genito-perineal raphe, that extends from the urethral meatus to the anus. Penile median raphe cysts are characteristically localized along the median line in the ventral aspect of the shaft. Cases of median raphe cyst of the penis with extension into the pelvis have been described. (4) Acquired forms can arise from occlusion of pilo-sebaceous unit or inclusion of epidermal cells within a circumscribed space of the dermis, usually after trauma or penile surgery.(5-7) Than they can occur anywhere in the penil shaft. Surprisingly the incidence of epidermal inclusion cysts after surgery is very low 
although theoretically any surgical procedure can predispose to them. Idiopathic forms have been described. (8) Epidermal cysts, congenital or acquired, of the penis can be single or multiple and of variable size. Characteristically they have a tendency to grow slowly, but they can reach big dimensions with time. The differential diagnosis of cystic structures in genital region includes an extensive range of conditions: urethral diverticula, urethrocutaneous fistula, dermoid cyst, teratoma. Physical examination and ultrasound or radiologic evaluation are useful to eliminate any doubt. (3) The best treatment is the surgical excision of the entire cystic lesion, because of the high possibility of recurrence with aspiration and simple drainage. $(1,5)$ Indications for surgical excision are cystic infection, pain, urethral obstruction because of the big dimension, cosmetic reasons. Follow-up after surgery is necessary to exclude recurrence. In our case the urethrocutaneous fistula is probably the result of the formation of the epidermal inclusion cyst. The coexistence of the two conditions is casual or the last is the cause of the former? Maybe the inflammatory reaction around the epidermal inclusion cyst interfered with the normal healing process, although the fistula appeared 1 year after urethroplasty. Therefore in our opinion surgical excision of epidermal inclusion cyst after urethroplasty must be performed as quickly as possible to avoid the appearance of urethrocutaneous fistulae.

\section{References}

Suwa M, Takeda M, Bilim V, Takahashi K. Epidermoid cyst of the penis:a case report and review of the literature. Int J Urol 2000; 7: 431-3.

Cimador M, Pensabene M, Sergio M, Catalano P, de Grazia E. Coverage of urethroplasty in pediatric hypospadias: Randomized comparison between different flaps. Int J Urol. 2013 Feb 20. doi: 10.1111/iju.12092.

Little Jr JS, Keating MA, Rink RC. Median raphe cyst of the genitalia. J Urol 1992; 148:1872-73

Rattan J, Rattan S, Gupta DK. Epidermoid Cyst of the penis with extension into the pelvis. J Urol 1997; 158:593.

LI., Okeke. Epidermal inclusion cyst as a rare complication of neonatal male circumcision: a case report. J Med Case Reports 2009; 3: 7321

Saini P, Mansoor M.N., Jalali S, Sharma A. Penile Epidermal inclusion Cyst. Indian J Pediatr 2010; 77(7):815-816

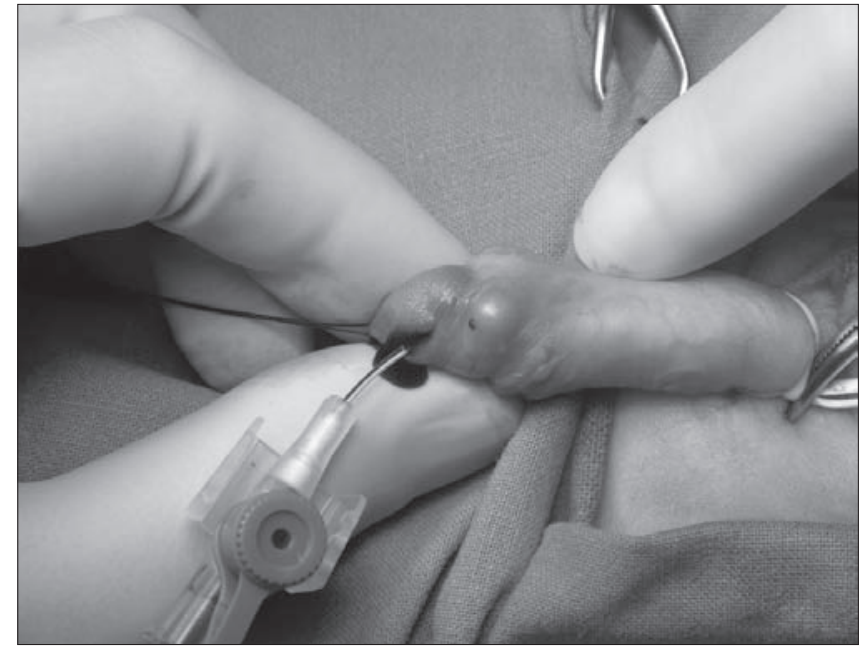

Figure 1.

Intra-operative appearance of epidermal cyst and pin-point urethro-cutaneous fistula at the top.

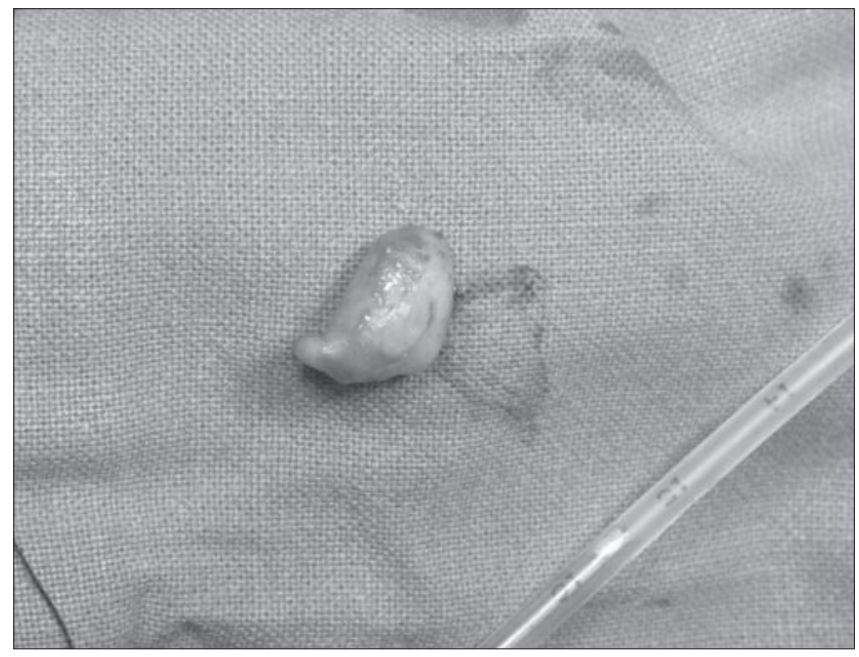

Figure 2.

Epidermal cyst removed

Park HJ, Park NC, Park SW, Jern TK, Choi KU. Penile epidermal inclusion cyst: a late complication of penile girth enhancement surgery. J Sex Med 2008; 5: 2238-2240

Aslan Y, Balci M, Atan A. Idiopathic penile epidermoid cyst in a young patient: three-year follow-up. Eur J Surg Sci 2011; 2(1):16-18. 